\title{
О СОСТАВЕ ОРГАНИЧЕСКОГО ВЕЩЕСТВА ТЕРМИЧЕСКИ ПРЕОБРАЗОВАННОГО ГОРЮЧЕГО СЛАНЦА СЕЛЕННЯХСКОГО ПОДНЯТИЯ СЕВЕРО-ВОСТОЧНОЙ ЯКУТИИ
}

\author{
(Представил О. Эйзен)
}

Девонские горючие сланцы (предположительно эйфельского яруса) на Селенняхском поднятии Верхояно-Чукотской складчатой области были обнаружены в 1978 г. в нижнем течении р. Талынджи (бассейн р. Индигирки). Суммарная мощность сланценосной серии, представленной часто чередующимися прослойками горючих сланцев, составляет около 15 м. Содержание органического вещества (OB) в сланцах колеблется в пределах $7-12 \%$, оно состоит в основном из коллоальгинита, минеральная часть - преимущественно из карбонатов и биогермного известняка. Для сланценосной толщи характерно присутствие асфальтов и асфальтитов в кавернах и трещинах. В геохимическом аспекте селенняхский сланец представляет интерес из-за определенной термической преобразованности его ОВ. Общая характеристика указанных сланцев дана в [ $\left.{ }^{1}\right]$, в настоящей работе приводятся дополнительные данные о составе битумоида и продуктов термической деструкции нерастворимой части ОВ сланца.

Битумоид выделяли из сланца исчерпывающей экстракцией хлороформом; кислотные соединения извлекали из битумоида 0,5 н. раствором гидроокиси калия в этиловом спирте. Полукоксование дебитумоидированного сланца проводили по ГОСТу 3168-66, фенолы выделяли из полученной смолы $10 \%$-ным водным раствором гидроокиси натрия. Нейтральную часть битумоида и смолы полукоксования разделяли на групповые компоненты методом тонкослойной хроматографии на силикагеле (элюент - $\mu$-гексан), полученные фракции анализировали газохроматографически с применением колонок различной полярности.

Характеристика исследовавшегося образца селенняхского сланца,

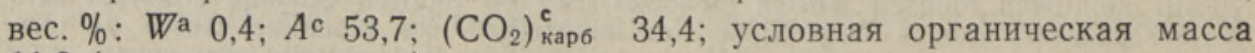
11,9 (на сухое вещество).

В результате экстракции было получено $0,49 \%$ битумоида на сухой сланец $(4,1 \%$ на ОВ), содержавшего $16,9 \%$ углеводородов (УВ), 37,1\% нейтральных гетероатомных соединений, 27,7\% эфнрорастворимых кислот и $18,3 \%$ высокомолекулярных, не растворимых в диэтиловом эфире кислотных соединений. Элементный состав битумоида, вес. \%: С 78,6; $\mathrm{H} 7,0 ; \mathrm{N} 0,6$; $(\mathrm{O}+\mathrm{S}) 13,8$; атомное отношение $\mathrm{H} / \mathrm{C}$ очень низкое $(1,07)$.

Преобладание гетероатомных компонентов характерно для сингенетичных битумоидов горючих сланцев, необычно в данном случае очень высокое содержание конденсированных ароматических УВ в углеводородной фракции битумоида. В таблице приведены полученные в Институте химии АН ӘССР по одинаковой методике данные о составе УВ битумоидов ряда сланцев; в этом отношении селенняхский сланец стоит ближе всего к доманиковому, отличаясь от него, однако, значительно 


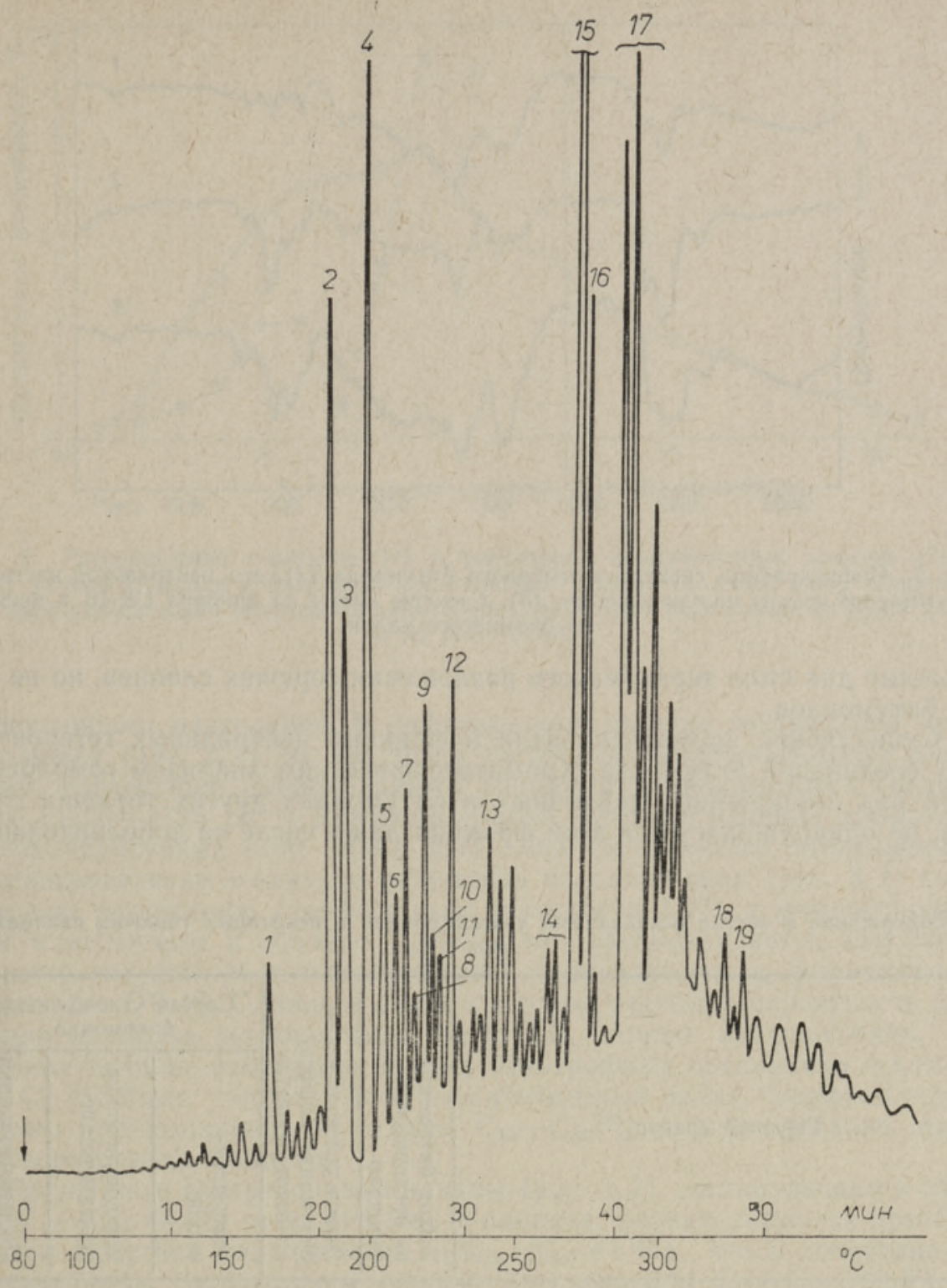

Рис. 1. Хроматограмма конденсированных ароматических углеводородов битумонда селенняхского сланца: 1 - нафталин, 2 - 2-метилнафталин, 3 - 1-метилнафталин, 4 - дифенил, 5 - 2-этилнафталин, $6-2,6$ - и 2,7-диметилнафталины, $7-1,3-1,6$ и 1,7-диметилнафталины, $8-1,4-, 1,5-$ и 2,3-диметилнафталины, 9 - 4-метилдифенил, 10 - 1,2-диметилнафталин, 11 - 3-метилдифенил, 12 - аценафтен +1,8-диметилнафталин, 13 - флуорен, 14 - метилфлуорены, 15 - фенантрен, 16 - антрацен, $17-$ метилфенантрены и метилантрацены, 18 - флуорантен, 19 - пирен. Колонка: $8 \%$ апиезона L на хромосорбе $\mathrm{W}-\mathrm{AW}-\mathrm{DMCS}, 0,15-0,18 ; 4,1 \times 3$ мм.

меньшим содержанием несвязанных УВ - результат более интенсивных эмиграционных процессов. Столь видная роль конденсированных ароматических УВ (свыше $50 \%$ от суммы УВ) свойственна также битумоидам каменных углей (напр., газового угля Фан-Ягнобского месторождения Таджикской ССР [2] и витринита жирного угля Кузбасса $\left.\left.{ }^{3}\right]\right)$.

Своеобразен также индивидуальный химический состав фракции конденсированных ароматических УВ битумоида (рис. 1): преобладают незамещенные и малозамещенные двухъ- и трехъядерные соединения, 


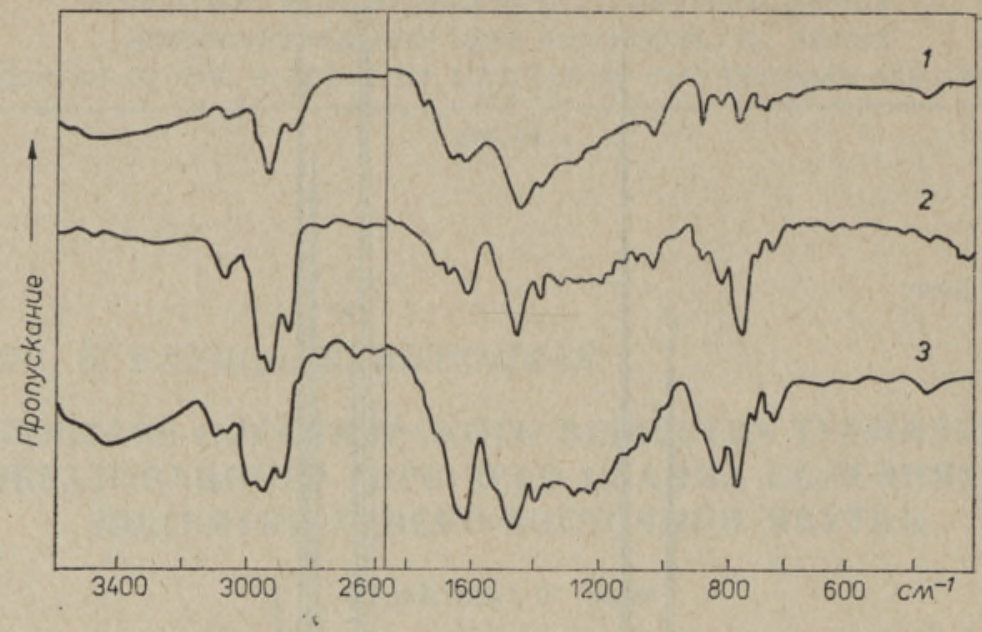

Рис. 2. Инфракрасные спектры суммарного битумоида (1), его нейтральной части (2) и суммарной смолы полукоксования (3). Спектры сняты на приборе UR-10 в кюветах из бромистого калия.

обычные для смол термического разложения горючих сланцев, но не для их битумоидов.

Существенно ароматизирована и фракция нейтральных гетероатомных соединений битумоида. Хроматографическим анализом гомологический ряд $н$-алканонов, найденных в битумоидах других горючих сланцев, не обнаруживается в этой фракции даже после ее дополнительного

Содержание и состав несвязанных углеводородов в некоторых горючих сланцах, вес. $\%$ *

Менилитовый УССР (палеоген)

Месторождения Боров Дол НРБ (эоцен)

Месторождения Капали УзбССР (эоцен)

Месторождения Гарибак ТаджССР (эоцен)

Ухтинский Коми АССР (юра)

Кашпирский Куйбышевской обл. (юра)

Кендерлыкский КазССР, караунгурская свита (пермь-карбон)

Любанский БССР (девон)

Ухтинский доманиковый Коми АССР (девон)

Селенняхский Якутской АССР (девон)

Кукерсит ЭССР (ордовик)

Тетрасписовый ЭССР (ордовик)

Диктионемовый ЭССР (ордовик)

Оленекский Якутской АССР (кембрий)

Алевролито-глинистый ӘССР (венд)

* В таблице использованы также данные И. Клесмента, М. Куузик и Л. Побуль. 


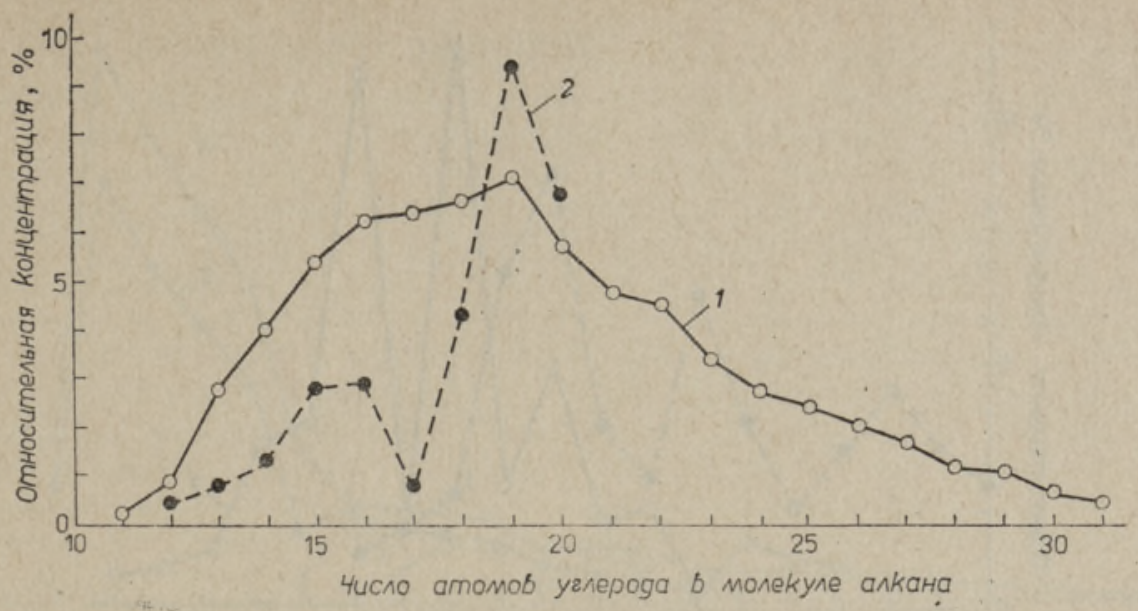

Рис. 3. Распределение н-алканов (1) и регулярных изопреноидных алканов (2) по числу атомов углерода в битумоиде селенняхского сланца по длине цепи. Концентрация дана относительно суммарного содержания соединений перечисленных групп (здесь и на рис. 4,5$)$.

тонкослойного разделения. В инфракрасном спектре нейтральной части битумоида (рис. 2,2 ), на две трети состоящей из гетероатомных соединений, поглощение карбонильными группами в ациклических соединениях (1700-1725 см $\left.\mathrm{cm}^{-1}\right)$ довольно слабое, зато поглощение ароматическими структурами $\left(750-900\right.$ и $\left.3030-3080 \mathrm{~cm}^{-1}\right)$ весьма интенсивное.

Распределение $н$-алканов битумоида по длине цепи (рис. 3,1 ) относительно монотонное (коэффициент нечетности 1,07) с концентрационным максимумом в области $\mathrm{C}_{15}-\mathrm{C}_{22}$, что рассматривается как свидетельство ведущей роли бактериальной биопродукции в формировании осадочного ОВ [4]. Однако в данном случае, учитывая вероятность эмиграции наиболее низкокипящей части УВ, можно предположить, что соответствующие продукции водных автотрофных организмов $H$-алканы (до $\mathrm{C}_{17}\left[{ }^{[5]}\right.$ ) были утеряны. Зато незначительный вклад биомассы терригенного происхождения (н-алканы $\mathrm{C}_{25}-\mathrm{C}_{33}\left[{ }^{6}\right]$ ) в формирование селенняхского сланца очевиден.

Регулярные изопренондные алканы (рис. 3,2 ), составляющие в области $\mathrm{C}_{12}-\mathrm{C}_{20} 64,3 \%$ от количества $\mathrm{H}$-алканов, характеризуются преобладанием пристана над фитаном $\left(i \mathrm{C}_{19}: i \mathrm{C}_{20}=1,44\right)$, что в сочетании со значительным содержанием низших изопреноидов $\mathrm{C}_{12}-\mathrm{C}_{18}(44,9 \%$ от идентифицированных изопреноидных алканов) указывает на существенную деградированность ОВ [7], в том числе, по нашему мнению, в результате термического воздействия.

Своеобразие содержащихся в битумоиде селенняхского сланца насыщенных жирных кислот (рис. 4) заключается в присутствии в них дикарбоновых кислот (51,3\% от суммы с монокарбоновыми), характеризующихся концентрационными максимумами при $\mathrm{C}_{7}, \mathrm{C}_{11}$ и $\mathrm{C}_{14}$, тогда как для современных осадков свойственны дикарбоновые кислоты $\mathrm{C}_{16}-\mathrm{C}_{28}$ при ярко выраженном преобладании «четных» гомологов $\left[{ }^{8}\right]$. Изопреноидные кислоты в исследовавшемся битумоиде представлены фитановой. В отличие от дикарбоновых, насыщенные монокарбоновые кислоты нормального строения имеют обычный для битумоидов малопревращенных горючих сланцев состав - доминируют $\mathrm{C}_{16}$ и $\mathrm{C}_{18}$, во всем ряду преобладают кислоты с четным числом атомов углерода в молекуле. Состав монокарбоновых кислот наводит на мысль о наличии автономного источника их генерации (иммиграции жирных кислот в породу 


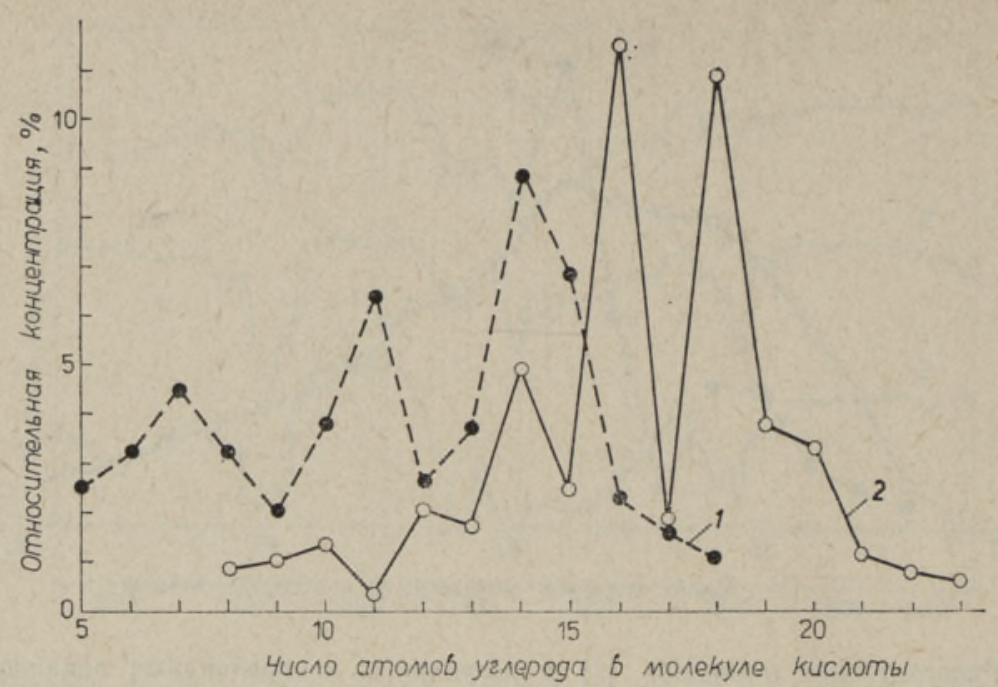

Рис. 4. Распределение по длине цепи насыщенных алифатических кислот нормального строения в битумоиде селенняхского сланца: дикарбоновые (1) и монокарбоновые (2) кислоты.

после завершения катагенетических процессов) или об их посткатагенетическом формировании в результате деятельности микроорганизмов на базе ОВ сланца как субстрата. Насыщенные монокарбоновые кислоты близкого состава были также найдены в битумоидах глубокопревращенного рифейского аргиллита Патомского нагорья $\left[{ }^{9}\right]$ и доманикового сланца Тимано-Печорской области [10].

Выход продуктов полукоксования на сухой сланец, вес. \%: смола 1,3; вода разложения 0,1 ; полукокс 96,4 ; газ и потери (по разности) 2,2 . Очень низкий выход смолы на ОВ $(10,9 \%)$ закономерен в свете данных о глубокой катагенетической преобразованности селенняхского сланца; его кероген является в сущности остатком частичной термической деструкции исходного ОВ.

Смола полукоксования содержит, вес. \%: неароматических УВ 10,9; моноциклических ароматических УВ 3,0 ; конденсированных ароматических УВ 29,2; нейтральных гетероатомных соединений 50,3 ; фенолов 6,6 . Элементный состав смолы, вес. \%: С 84,1; Н 8,2; гетероатомы 7,7; атомное отношение H/C 1,17. Ароматизированность смолы ясно подтверждает ее инфракрасный спектр (рис. 2).

Идентифицированные в смоле $H$-алканы $\mathrm{C}_{7}-\mathrm{C}_{31}$ (рис. 5) характеризуются монотонным распределением по длине цепи (коэффициент нечетности 0,97 ) и низкой концентрацией твердых парафинов, что присуще высокопревращенным керогенам нетерригенной природы; подобную кривую распределения имеют также $\boldsymbol{H}$-алканы смолы из доманикового сланца $\left[{ }^{10}\right]$. -1-Алкены, присутствующие во всех сланцевых смолах, составляют в исследовавшейся смоле $66,2 \%$ от количества $\boldsymbol{н}$-алканов; нередко встречающегося в сланцевых смолах преобладания «четных» гомологов не наблюдается.

Необычно значительное содержание регулярных изопреноидных алканов $\mathrm{C}_{12}-\mathrm{C}_{20}$ в смоле $\left(31,6 \%\right.$ от количества $H$-алканов $\left.\mathrm{C}_{12}-\mathrm{C}_{20}\right)$, что, с учетом их высокой концентрации в неароматических УВ битумоида, который сам частично является продуктом термолиза керогена, говорит о видной роли изопреноидных структурных элементов как в исходном OB, так и в керогене селенняхского сланца на современной стадии его развития. Выраженное преобладание пристана над фитаном в смоле 
термолиза исследовавшегося сланца признаков, характерных для горючих сланцев липидно-липондного происхождения [11], является результатом катагенетической трансформированности ОВ. Обращает также внимание относительно высокое содержание водорода в газе полукоксования, что согласуется с представлениями о возрастании миграционной способности водорода по мере ароматизации керогена.

Своеобразие селенняхского сланца заключается прежде всего в высокой степени термодеградированности его ОВ, наиболее ярко проявляющейся в составе конденсированных ароматических УВ битумоида, и в обогащенности нерастворимой части ОВ изопреноидными структурными элементами. K сожалению, геологические причины термодеградированности данного сланца были ['] и остаются пока не выясненными из-за отсутствия явных следов контактного метаморфизма. Наиболее вероятно предположение, что рассматриваемый случай является следствием термального воздействия на сланценосную толщу какой-то погребенной гранитоидной интрузии, которая на этом участке не вскрыта эрозией. Район Селенняхского поднятия, приуроченный к внешней зоне миогеосинклинали Верхояно-Чукотских мезозоид, изобилует мощными гранитоидными телами. Остывание подобных тел даже в геологических масштабах, как известно, занимает немалый отрезок времени, что, конечно, не могло не оказать соответствующего влияния на вмещающие осадочные породы и заключенное в них ОВ.

\section{ЛИТЕРАТУРА}

1. Клубов Б. А., Уров К. Э. Девонские горючие сланцы Селенняхского поднятия (Северо-Восточная Якутия). - Докл. АН СССР, 1979, 247, № 5, 1257-1260.

2. Урмет Э. А., Бурякова Э. П., Румянцева З. А., Клесмент И. Р., Уров К. Э. Хроматографический анализ экстрактов и продуктов пиролиза среднеазиатского каменного угля. - Хим. тверд. топл., 1977, № 2, 78-83.

3. Клесмент И., Уров К., Куузик М., Высоцкая В. Характеристика битумонда и смолы полукоксования витринитового каменного угля Кузбасса. - Изв. АН ЭССР. Хим., 1980, 29, № 2, 77-83.

4. Johnson, R. W., Calder, J. A. Early diagenesis of fatty acids and hydrocarbons in a salt marsh environment. - Geochim. et cosmochim. acta, 1973, 37, N 8, 1943-1955.

5. Mathews, R. T., Cook, A. C., Johns, R. B. Relation between n-alkane distribution and effective coalification temperatures in some Permian shales. - Geochim. et cosmochim. acta, 1975, 39, 1237-1243.

6. Тиссо Б., Вельте Д. Образование и распространение нефти. М., 1981, 103.

7. Шляхов А. Ф., Волкова Л. Г. Стереохимня изопреноидных алканов и возможные пути нх образования в осадочных породах. - Геохимия, 1977, № 9, 1418-1423.

8. Volkman, J. K., Johns, R. B., Gillan, F. T., Perry, G. J. Microbial lipids of an intertidal sediment. I. Fatty acids and hydrocarbons, - Geochim. et cosmochim. acta, 1980, 44, 1133-1143.

9. Уров К., Листрем А., Яанус А. Сравнительная характеристика органического вещества докембрийских сланцев Эстонской ССР и Иркутской области. - Изв. АН ЭССР. Хим., 1979, 28, № 2, 71-79.

10. Уров К. Э., Листрем А. Н. Сравнительная характернстика органического вещества девонского и юрского горючих сланцев Ухтинского месторождения. - Хим. тверд. топл., 1977, № 2, $71-77$.

11. Уров $K$. Состав газообразных продуктов термолиза как диагностический признак генетического типа каустобнолита. - Изв. АН ЭССР. Хим., 1980, 29, № 4 , $246-250$.

Ннститут химии

Академии наук Эстонской ССР
Поступила в редакцию

18/XI 1983

Северо-Восточный комплексный ННИ

Дальневосточного научного центра

Академии наук СССР (Магадан) 


\title{
KIRDE-JAKUUTIA SELENNJAHHI TERMILISELT MUUNDUNUD POLEVKIVI ORGAANILISE AINE KOOSTISEST
}

Nafta genereerimise staadiumi jõudnud Selennjahhi põlevkivi (devon) bitumoidile on iseloomulik kõrge aromaatsete (72\% kõigist süsivesinikest), eriti polütsükliliste süsivesinike kontsentratsioon. Nimetatud süsivesinikud on oma keemiliselt koostiselt lähedased pōlevkivi utteõlis sisalduvaile süsivesinikele ja neile on iseloomulik tavalisest suurem isoprenoidsete alkaanide (neist $45 \%$ madalamaid $\mathrm{C}_{12}-\mathrm{C}_{18}$ homolooge, suhe pristaan : fütaan on 1,44 ) ja küllastunud alifaatsete dikarboksüülhapete (üle $50 \%$ kõigist küllastunud alifaatsetest hapetest) sisaldus. Orgaanilise aine lahustumatu osa kujutab endast lähtekerogeeni osalise termilise lagunemise produkti, mistõttu selle utteõli saagis on madal $(11 \%)$.

\author{
K. UROV, B. KLUBOV, V. VYSSOTSKAYA
}

\section{ON THE COMPOSITION OF ORGANIC MATTER OF THERMALLY DEGRADED SELENNYAKH OIL SHALE OF NORTH-EAST YAKUTIA}

A high relative concentration of aromatic hydrocarbons ( $72 \%$ of all hydrocarbons), especially polycyclic ones, which are similar in their chemical composition to those present in the shale semicoking oil, as well as a considerable amount of aliphatic isoprenoid hydrocarbons $\left(45 \%\right.$ of which are lower homologues $\mathrm{C}_{12}-\mathrm{C}_{18}$, the pristane : phytane ratio being 1.44) and saturated aliphatic dicarboxylic acids (over $50 \%$ of total saturated aliphatic acids) - those are the characteristic features of the bitumen of the Devonian Selennyakh shale that has reached the main oil formation stage. The insoluble part of the shale organic matter may be regarded as the product of partial thermal decomposition of the initial kerogen, and therefore its semicoking oil yield is low $(11 \%)$. 